Bentham OPEN

RESEARCH ARTICLE

\title{
Enhanced Teamwork Communication Model for Electronic Clinical Pathways in Healthcare
}

\author{
Wasef Mater ${ }^{1, *}$, Monther Aldwairi ${ }^{2,3}$ and Roliana Ibrahim ${ }^{4}$ \\ ${ }^{l}$ E-Business \& Commerce Department, Faculty of Administrative \& Financial Sciences, University of Petra, Amman, \\ Jordan \\ ${ }^{2}$ College of Computer and Information Technology, Jordan University of Science and Technology, Irbid, Jordan \\ ${ }^{3}$ College of Technological Innovation, Zayed University, Abu Dhabi, UAE \\ ${ }^{4}$ Department of Information System, Faculty of Computing, Universiti Teknologi Malaysia, Johor, Malaysia
}

Received: October 18, 2017

Revised: May 25, 2018

Accepted: June 11, 2018

\begin{abstract}
:
Background:

One of the main challenges to hospital patient flow and treatment includes the lack of a patient-centered approach, which in turn contributes to non-effective teamwork communication.
\end{abstract}

\section{Objectives:}

To introduce patient-centered approach by implementing electronic clinical pathways to support more effective teamwork communication. To study how to enhance teamwork communication in healthcare by implementing electronic clinical pathways.

\section{Methods:}

We propose a research model, integrating the Donbedian model and the socio-technical theory, to investigate the factors that influence teamwork communication in healthcare. This research applied a quantitative approach using a survey method that was designed along the same principles as in the related work. Preliminary data collection was conducted using the survey method for problem formulation.

\section{Results:}

Designed and developed a model for implementing electronic clinical pathways to enhance teamwork communication in healthcare.

\section{Conclusion:}

This study provides recommendations to hospitals to enhance teamwork communication in healthcare by implementing electronic clinical pathways.

Keywords: Clinical pathways, Communication, Healthcare, Socio-technical theory, Donabedian model, Electronic clinical pathways.

\section{INTRODUCTION}

The disease-centered approach has been the dominant form of healthcare delivery. In a disease-centered delivery, patients are treated by specialists, without consideration for other medical conditions or medications. Recently, there has been a shift towards a more patient-centered approach, where healthcare delivery keeps in mind all other present

\footnotetext{
"Address correspondence to this author at the E-business and Commerce Department, Faculty of Administrative \& Financial Sciences, University of Petra, P.O. Box 961343, Amman 11196, Jordan; Tel: +962 6 5715570; E-mail: wasef.matar@uop.edu.jo
} 
conditions. For that to happen, high levels of collaboration and communication among healthcare providers are imminent. This results in better use of resources, better care delivery and fewer diagnostic conflicts.

Clinical pathways $[1,2]$ play an instrumental role in the patient-centric healthcare model. They are an international standard that defines a step-by-step treatment path to follow. This means successful communication and collaboration of the main stakeholders in the treatment process. That is physicians, specialists, nurses, emergency room coordinators, administrative staff and pharmacists must work as one team. However, every patient's treatment process is special and might follow different paths as opposed to other patients. The communications among stakeholders might follow different channels. Moreover, patients with multiple symptoms might follow multiple clinical pathways. Therefore, effective communication among medical staff is essential along all these different clinical pathways. These communications might occur across departments, healthcare facilities and time boundaries. Consequently, treating one patient might include multiple departments, campuses, hospitals, specialists and drugs. This requires high levels of coordination amongst all the above to avoid costly mistakes that will endanger lives.

A comprehensive literature review revealed that there is little research looking at clinical pathways from information systems and teamwork communication perspectives. In addition, there are very few models for implementation and adoption in Healthcare Information Systems (HIS), and the existing models are not extensive and rigorous [3]. Consequently, there is a need for a more comprehensive and rigorous teamwork communication model that takes into account and aligns with social and technical aspects.

Seventy percent of medical errors are attributed to teamwork communication [4]. Communication can be synchronous and asynchronous, with both having advantages and disadvantages. In using synchronous and asynchronous communication, the most important issue is the lack or inconsistency of patients' information [5 - 7]. To confirm and apply the patient-centred approach, there is a need for information systems to support the treatment process. This is lacking in the current HISs, which leads to delay in communications due to inaccessibility of medical records [8]. Therefore, healthcare information systems must provide support for better teamwork communications and information sharing in the clinical pathway.

Today, healthcare providers follow a legacy manual patient-centered treatment delivery system, which has many limitations. To overcome these limitations, as well as provide better teamwork communication and support for care coordination, healthcare professionals use synchronous and asynchronous approaches. Synchronous communication includes phone and video calls in addition to in-person meetings. Asynchronous communication includes fax, e-mail, and snail mail. All of the aforementioned communication approaches suffer from a lack of reliability, availability, accessibility and accuracy needed to effectively improve teamwork communication [8, 9]. In addition, healthcare communications are sensitive to confidentiality, integrity and timely availability of data.

\section{THEORETICAL BACKGROUND}

This section presents a review of related work on Information Systems (IS) theories and teamwork communication models with the aim of developing a new model to enhance teamwork communication in healthcare.

\subsection{Information Systems and Teamwork Communication Considerations}

This research study attempts to highlight the factors that affect the enhancement of teamwork communication by implementing electronic clinical pathways. In spite of the advantages of clinical pathways for teamwork communication, less attention has been paid to exploring physicians and nurses' use of communication throughout clinical pathways. More than 50\% of HISs around the world have failed and very few models incorporate electronic pathways in HISs [3]. In addition, there is a trend to enhance communication and decision making in HISs, which has not yet been achieved [10].

This research study seeks to enhance teamwork communication in healthcare by implementing electronic clinical pathways. The socio-technical theory and the Donabedian model are integrated for that purpose. In socio-technical theory, IS comprises two subsystems: The technical (technology and process) and the social (people and structure). To attain the full benefits, system designers and developers have to identify how subsystems impact each other [11, 12]. To enhance the current HISs, there is a need for alignment between technical and social aspects to prevent the failure of systems $[13,14]$.

Many studies have considered how the quality of healthcare systems may be evaluated and assessed [15, 16]. The Donabedian model explains three dimensions (structure, process, outcome), which present the whole structure for any 
information system. Kuziemsky et al, [17] used the Donabedian model to develop an interdisciplinary team communication model. This framework supports interdisciplinary team communication and can serve as a guideline for developers and designers when implementing HISs that support teamwork communication.

\subsection{Health Information System Approaches}

The current HISs were designed for organizational purposes; thus there is a need to distinguish between the administrative and clinical processes. The current HISs support the administrative processes, but to a limited degree, they include some clinical processes that can support teamwork communication. Consequently, the current HIS has not been designed to support the patients' treatment processes and does not support communication and coordination of multiple teamworks [18 - 21]. HISs have two approaches: the disease-centered and the patient-centered. In the diseasecentered approach, physicians treat their patients individually, without considering other conditions and treatments. There is a need to switch from the disease-centered to the patient-centered approach to treat the patient's case as a whole instead of isolated diseases $[18,19,22]$. This approach can support the administrative process, not the clinical processes; in other words, it supports the administrative purpose, and there is a need for a system supporting the clinical processes. This approach lacks supporting teamwork activities, especially communication, and lacks information on the treatment process flow. In addition, it lacks information on when the patient's disease reached its current stage and what the future implications might be. In a patient-centered approach, physicians treat their patients and take into account all the patient's diseases as a whole, not in isolation from other conditions. The aim of this approach is to enhance the quality of healthcare and reduce errors. The patient-centered approach supports teamwork activities, and these activities have a primary element that is depicted in communication and coordination. There are two key requirements of the patient-centered approach, teamwork communication and care coordination [18, 19, 22 - 24]. The patient-centered approach has a set of characteristics illustrated in Table 1 [25 - 27]. The patient-centered approach supports teamwork activities, including communication and coordination. Finally, effective teamwork communication remains a problem in healthcare due to adverse negative outcomes [28].

Table 1. Patient-centered approach characteristics.

\begin{tabular}{|c|c|c|}
\hline $\begin{array}{c}\text { HISs Characteristics-based Patient-centered } \\
\text { Approach }\end{array}$ & Characteristics Illustrations & References \\
\hline $\begin{array}{c}\text { Communication } \\
\text { Decision Support }\end{array}$ & $\begin{array}{c}\text { Plays a key role in healthcare delivery. We can classify communication mainly into two } \\
\text { types: } \\
\text { synchronous and asynchronous }\end{array}$ & $\begin{array}{c}\text { To help healthcare professionals make decisions at the point of care both in diagnosis } \\
\text { and treatment processes. }\end{array}$ \\
\hline Collaboration & $\begin{array}{c}\text { Helps healthcare professionals to deliver the care for all patients. Collaborative care has } \\
\text { four elements of care delivery: } \\
\text { Patient awareness } \\
\text { Team member awareness } \\
\text { Decision-making awareness } \\
\text { Environment awareness }\end{array}$ & {$[30]$} \\
\hline Education and Knowledge Translation & To provide training for healthcare professionals in order to enhance healthcare quality. & - \\
\hline Continuity of Care & Provide a healthcare with high quality and low cost. & {$[31]$} \\
\hline
\end{tabular}

\subsubsection{Teamwork Communication in Healthcare}

Teamwork is a new concept in healthcare. Also, there is a lack of shared decision-making and interdependent collaboration between team members [32] even though communication systems are comprised of messages, people, and transmission systems [33]. In recent years, much research has been conducted to improve teamwork communication $[32,34]$. Improving teamwork communication requires redesigning the work and process to support more effective communication [35]. The clinical pathways concept and structure supports the patient-centered approach and provides a solution for teamwork communication but more research is still needed. Table 2 presents the trends in teamwork communication in healthcare and the gaps. Consequently, based on Table 2, research on teamwork communication in healthcare is still in its infancy stage. There is need for more research and specific research work on such tools and system which improve and enhance teamwork communication in healthcare. 
Table 2. Trends in teamwork communication in healthcare.

\begin{tabular}{|c|c|c|}
\hline Reference and Title & Summary & Future Work and Gaps \\
\hline $\begin{array}{c}\text { Improving Clinical } \\
\text { Communication: } \\
\text { A View from Psychology [36]. }\end{array}$ & $\begin{array}{l}\text { The current communications (synchronous } \\
\text { communication) have negative effects on task load. }\end{array}$ & $\begin{array}{l}\text { Using information technology to support } \\
\text { teamwork communication among medical staff. }\end{array}$ \\
\hline $\begin{array}{l}\text { Communication Systems in Healthcare } \\
\qquad[33] .\end{array}$ & $\begin{array}{c}\text { Less attention is paid to communication systems and } \\
\text { many health services are yet to fully embrace the } \\
\text { clinical adoption of services like voice-mail or } \\
\text { electronic mail. }\end{array}$ & $\begin{array}{l}\text { The attention paid to communication support is } \\
\text { still quite imbalanced. } \\
\text { More attention needs to be paid to } \\
\text { communication enhancements in healthcare. }\end{array}$ \\
\hline $\begin{array}{l}\text { Intra-organizational Communication } \\
\text { in Healthcare [29]. }\end{array}$ & $\begin{array}{l}\text { Inefficiency and error in healthcare often result from } \\
\text { synchronous interruptive communication }\end{array}$ & $\begin{array}{l}\text { The current communication channels have } \\
\text { negative effects on healthcare quality, and this } \\
\text { situation affords fresh insights into IT } \\
\text { applications for improving interpersonal } \\
\text { communication. }\end{array}$ \\
\hline $\begin{array}{l}\text { An interdisciplinary team communication } \\
\text { framework and its application to } \\
\text { healthcare'e-teams' systems design [17]. }\end{array}$ & $\begin{array}{l}\text { Creating a framework for interdisciplinary team } \\
\text { communication based on processes, structures, and } \\
\text { outcomes. }\end{array}$ & $\begin{array}{l}\text { Using IT to support teamwork communication in } \\
\text { healthcare }\end{array}$ \\
\hline $\begin{array}{l}\text { Describing the Clinical Communication } \\
\text { Space a Model of Common Ground: ‘you } \\
\text { don't know what you don't know' [37] }\end{array}$ & $\begin{array}{l}\text { Understanding how to deliver collaborative care } \\
\text { through custom designed communication systems. }\end{array}$ & $\begin{array}{l}\text { This is just a an introductory work into the design } \\
\text { of clinical communication systems. }\end{array}$ \\
\hline $\begin{array}{c}\text { The Effect of Health Information } \\
\text { Technology on Health Care Provider } \\
\text { Communication: A Mixed-Method Protocol } \\
{[38]}\end{array}$ & $\begin{array}{c}\text { A theoretical model that is based on communication } \\
\text { and sociology theories covers how communication is } \\
\text { affected by health information and communication } \\
\text { technologies. }\end{array}$ & $\begin{array}{l}\text { Identification of those health information and } \\
\text { communication technologies that support mutual } \\
\text { understanding between physicians and nurses is } \\
\text { an aim of this study. }\end{array}$ \\
\hline
\end{tabular}

\subsection{Clinical Pathways}

The European Pathway Association (EPA) defines clinical pathway as mutual healthcare processes, steps and decisions for similar patients during the same period. The defining characteristics of the clinical pathways include:

1. Clear healthcare elements from past experience;

2. Enhanced communication between healthcare professionals and with patients and families;

3. Clear sequence of steps for healthcare delivery and well-coordinated roles for healthcare professionals, patients and families;

4. Documentation, checking, and assessment of outcomes; and

5. List of appropriate resources.

Clinical pathways help implement patient-centered healthcare to reduce cost and improve care. One method of enhancing the quality is to redesign the healthcare processes, with the aim of enhancing teamwork communication. To achieve this aim, electronic clinical pathways should be adopted to utilize resources better $[39,40]$.

Clinical pathways facilitate the flow of medical records and data through the treatment and reduce medical errors [41]. Medical errors can be divided into diagnostics, treatment, preventive, and others [42]. A good number of those errors result from the lack of communications as well as improper sharing of data in terms of accuracy and timeliness. Improving the treatment process plays a major role in reducing medical errors. clinical pathways will improve the outcomes of the treatment process. They present the treatment process and design the patient journey by managing the timing, using of Gantt charts, for example [43].

\subsubsection{Clinical Pathways Analysis Situation}

In spite of the increase in the number of studies on clinical pathways both in the medical domain and in other domains, clinical pathways have continued to be promoted as a communication medium. However, few studies on clinical pathways emanate from Information Systems to help establish it as a reliable means for improving healthcare quality as well as improving and enhancing teamwork communication among medical staff. In the healthcare domain, some tools are deployed to improve communication among medical staff. These include SBAR (Situation, Background, Assessment, and recommendation), a structured communication technique aimed at standardizing communication among medical staff $[44,45]$, and TeamSTEPPS (Team Strategies and Tools to Enhance Performance and Patient Safety), which provides a framework for performance and safety [46, 47]. These tools enhance communication among medical staff, but shortcomings exist in the way of providing the information. These shortcomings are based on clinical pathways. 
This situation analysis of clinical pathways suggests the future existence of work about it as a medium of communication in healthcare quality. There is little research on teamwork communication in healthcare [48], and there are gaps between teamwork and teamwork deficiencies [49]. Thus there is a need for more research from the perspective of information system. clinical pathways have an effect, which promotes communication among healthcare professionals [1, 50]. However, few studies of teamwork using clinical pathways exist [1, 51]. Moreover, for effective healthcare management, promotion communication among healthcare professionals by clinical pathways activities is crucial.

Communication among healthcare professionals is typically hierarchical. Hierarchical communication is ineffective in the teamwork of diverse healthcare professionals. Flat communication encourages effective teamwork in healthcare $[1,52]$.

When it comes to setting "outcome", the conversations among diverse healthcare professionals, are aimed at determining the appropriate healthcare process for a patient. In setting outcome, respect for diverse kinds of knowledge is required to communicate the conversation. Thus, this conversation flat and electronic clinical pathways enables flat communication [1].

Communication to understand different knowledge among various professionals is improved through clinical pathway activities in healthcare. There is need for directors of clinical pathway activities to consider the importance of the sustainment of flat communication.

A study was carried out on clinical pathways for four years from 2011 to 2014 using Google Scholar. This study aims to study the trend and reveal, which discipline concentrates on clinical pathways. Table 3 expresses the studies on clinical pathways based on four disciplines. Also, Table 4 shows the perspective from which each discipline studies clinical pathways. Fig. (1) is a chart showing the papers published per domain. This study opens new areas to study clinical pathways from four disciplines: computer science, medicine, management and information system.

\section{Percentage Per Domain (2011-2014)}

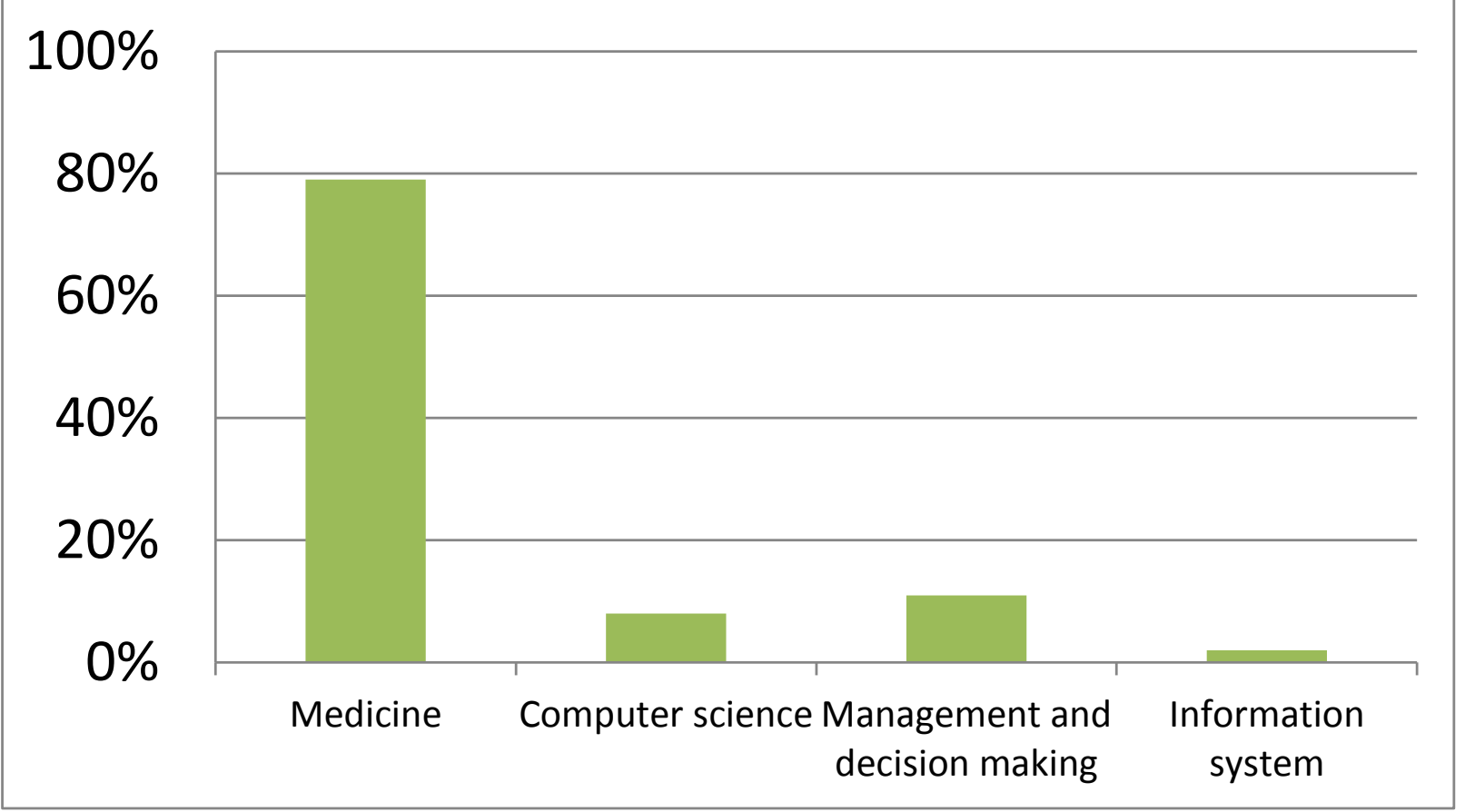

Fig. (1). Percentages of papers published per domain. 
Table 3. Clinical pathways disciplines.

\begin{tabular}{|c|c|c|c|c|}
\hline \multirow{2}{*}{ Year } & \multicolumn{4}{|c|}{ Domain } \\
\hline & Computer Science & Medicine & Management and Decision Making & Information System \\
\hline 2011 & 5 & 58 & 7 & 3 \\
\hline 2012 & 13 & 82 & 13 & 1 \\
\hline 2013 & 13 & 95 & 19 & 0 \\
\hline 2014 & 8 & 113 & 11 & 5 \\
\hline Total per domain & 39 & 348 & 50 & 9 \\
\hline Percentage per domain & \begin{tabular}{|l|}
$8 \%$ \\
\end{tabular} & $79 \%$ & $11 \%$ & $2 \%$ \\
\hline \multicolumn{3}{|c|}{ Percentage of all domains versus medicine } & \multicolumn{2}{|l|}{$21 \%$} \\
\hline
\end{tabular}

Table 4. Clinical pathways domain perspective.

\begin{tabular}{|c|c|c|}
\hline Reference & Domain of Study & Comments \\
\hline \multirow{3}{*}{$\begin{array}{l}{[53]} \\
{[54]} \\
{[55]}\end{array}$} & \multirow{3}{*}{ Medical } & Assessing clinical pathways on improving the quality of healthcare \\
\hline & & Effect on breast cancer patients \\
\hline & & Effect of clinical pathways on healthcare quality \\
\hline \multirow{3}{*}{$\begin{array}{l}{[56]} \\
{[57]} \\
{[58]}\end{array}$} & \multirow{3}{*}{ Computer science } & Using modeling approach to improve healthcare delivery \\
\hline & & Summarizing clinical pathways from event logs by using process mining \\
\hline & & Designing and implementing software for clinical pathways \\
\hline \multirow{3}{*}{$\begin{array}{l}{[59]} \\
{[60]} \\
{[61]}\end{array}$} & \multirow{3}{*}{ Management and decision making } & Developing a framework for knowledge management \\
\hline & & Adopting quality framework to ensure the quality of care provided to all patients \\
\hline & & Proposing a framework for the influence of clinical pathways on patient safety \\
\hline \multirow{2}{*}{$\begin{array}{l}{[8]} \\
{[4]}\end{array}$} & \multirow{2}{*}{ Information System } & Using a Business Processes Management (BPM) system to develop clinical pathways \\
\hline & & Investigating factors that enhance teamwork communication which is affected by clinical pathways \\
\hline
\end{tabular}

The above situational analysis of clinical pathways leads the researcher to look for developing models and frameworks to enhance teamwork communication in healthcare. The next section illustrates these models and discusses their characteristics.

\subsection{Limitations}

There is a lack of investigated factors in support of teamwork communication in healthcare. By implementing clinical pathways, the lack of these factors is exposed. Based on these gaps, there is a need to look for a theory or a model to enhance teamwork communication in healthcare. The theory or model should support implementation, development and design. These gaps appear in the inability of supporting clinical pathway processes, such as communication protocols which are useful in supporting standardized communication among medical staff, structuring internal and external communication, sharing and exchanging information among medical staff.

Table 5 explains the gaps in the investigated factors [62]. Clinical pathways have three processes [63]: The medical process, the administrative process, and the decision-making process. Based on these processes, there is a need to adopt a set of factors or a model to support the mentioned processes of clinical pathways. Based on these issues in this research study, there is a need for a model or a framework to solve these problems. The gaps of these factors, based on matching the issues using clinical pathways processes, are listed below.

First, the initial process of clinical pathways is the medical process. During the matching of the factors to the medical process, we found that no factors support the medical process. In the medical process, there is a need for a set of factors to support the medical process for patients from admission to discharge to make sure that all medical stages are verified and supported to improve healthcare quality and patient safety. In electronic clinical pathways, 5 characteristics of clinical pathways describe medical process structure. Consequently, these characteristics of the medical process have the ability to solve the issues of lack of a system that supports the treatment process and lack of information about the patients' plan. 
Table 5. Gaps of investigated factors.

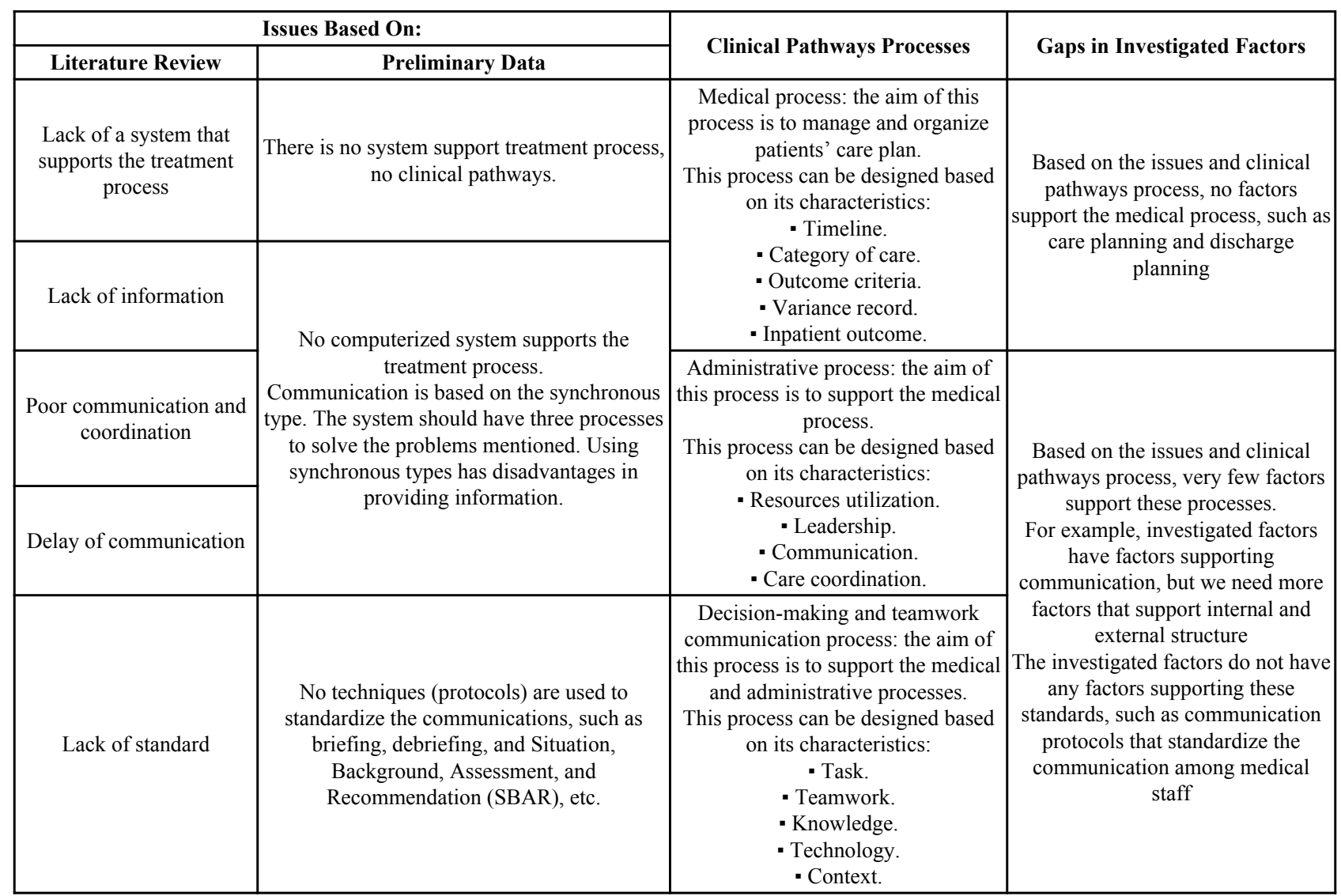

Second, very few factors support the administrative process, the decision-making process, teamwork communication that can solve the issues that are depicted in poor communication and coordination, and delay of communication. The characteristics of these processes need a set of factors to solve the issues and provide a solution to these issues.

Based on the above discussion and the gaps of the investigated factors, there is a need to investigate a theory or a model with its factors to support clinical pathways processes and solve the issues.

\subsection{Statement of Methods and Systematic Literature Review}

To identify the related researches, we searched three online databases: Medline (PubMed), ScienceDirect, and Scopus, for papers published between January 2010 and December 2013. In addition, Google Scholar was searched to do a more thorough literature search. Three factors effect teamwork communication: teamwork, task, and context. Most of the literature focuses on the teamwork concept, and very little attention is paid to the other two factors. Task and context factors have considerable effects on teamwork, especially in healthcare multidisciplinary teamwork. We wanted to study all factors affecting teamwork communication and what factors and indicators contribute to the success of teamwork communication.

The following systematic review study guided our related literature search [64]. The following search parameters were used: "clinical pathways" or "critical pathway" or "integrated care pathway" or "care map" $\}$ and \{"communication" and ("teamwork" or "team")\}; period: \{January 2010 to December 2013\}; limit to "English language", "abstract", "full text". Medline search produced 346 hits, Scopus produced 206 hits, and ScienceDirect produced 82. A total of 634 papers are identified (Fig. 2). 


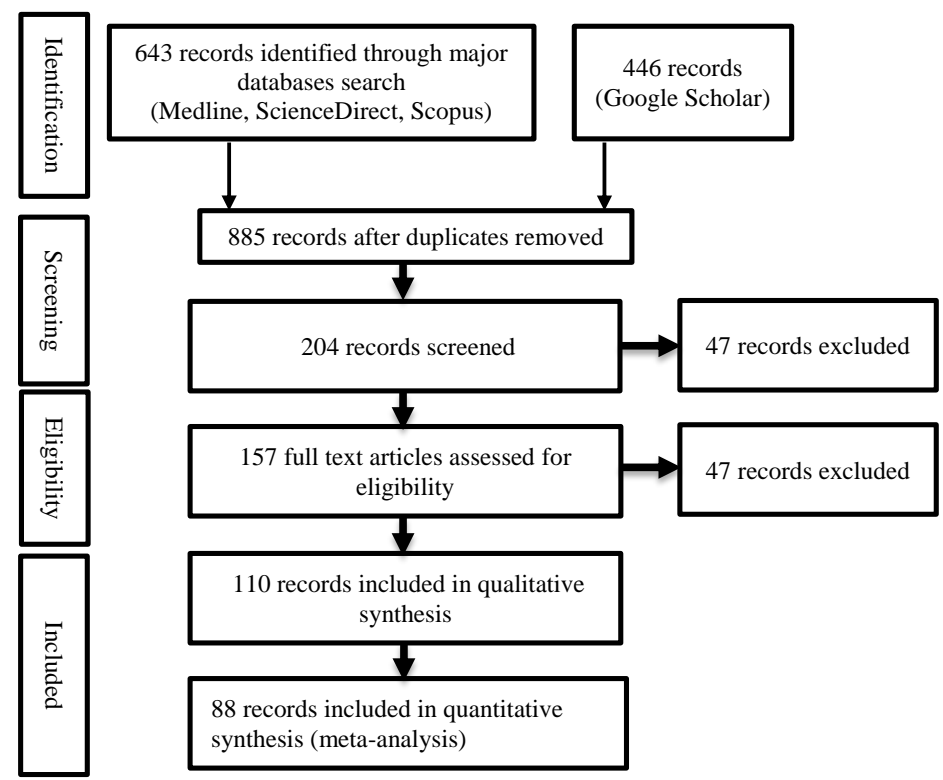

Fig. (2). PRISMA flowchart.

\subsection{Summary of Literature Findings}

We surveyed information system studies that discuss HIS and clinical pathways, clinical pathways studies in information systems given the problematic history of HIS issues related to a lack of specific details and failure in HIS implementations, and the issues related to HIS and clinical pathways [3, 65]. The studies present the current state of the art in addressing teamwork communication in healthcare. It is apparent that researchers and medical staff in the healthcare domain are expressing their concerns about these issues and are engaging in attempts to mitigate these concerns [66]. To date, however, teamwork communication in healthcare has not been adequately addressed, and the issues require further investigation [67]. It is apparent that it is important to consider social and technical factors that enhance teamwork communication in healthcare.

The current Health Information System is a disease-centered approach [68]. This approach has weaknesses to support the teamwork communication, and there is a need to switch to a patient-centered approach. Teamwork communication is a key point of the patient-centered approach. The present patient-centered approach is crucial to facilitate identifying the appropriate factors for enhancing teamwork communication in healthcare to apply the patientcentered approach.

In health informatics science, we must have a model before automating any processes or systems. At present, there is a rush in designing ICT systems for healthcare without an articulate model or framework on how the processes and systems will work [25, 68, 69]. Improving Health Information Systems by adopting the patient-centered approach as a new concept to enhance teamwork communication and improve the healthcare service quality needs to implement clinical pathways as one of the systems that support the concept of a patient-centered approach. Enhancing teamwork communication in healthcare by implementing clinical pathways to apply the concept of a patient-centered approach by using the social-technical system to align the social and technical aspects will improve healthcare service quality and patient safety.

\section{RESEARCH FRAMEWORK}

We seek to integrate the socio-technical theory and the Donabedian model to enhance teamwork communication in healthcare by implementing electronic clinical pathways. Subsection 3.1 explains the development model; subsection 3.2 describes the Donabedian model, which plays a key role in developing the developed model in this research, and Subsection 3.3 describes the research hypotheses.

\subsection{Model Development}

Fig. (3) depicts the socio-technical theory's two aspects or subsystems: social and technical. Each aspect's component has an interactive relationship with another aspect's component. Interacting here means how every aspect supports the other aspect. Fig. (4) depicts the Donabedian model. There are three dimensions to enhance healthcare 
system's quality in general and to improve the proposed framework to enhance teamwork communication in healthcare in particular [17]. For this study, the enhancement of teamwork communication in healthcare by implementing electronic clinical pathways is represented as a socio-technical system by adapting Donabedian framework factors to the socio-technical theory. In addition, we improve the Donabedian framework by adding communication protocols' factor to make the Donabedian framework more comprehensive and supportive for clinical pathways processes [70], especially because communication protocols have the ability to standardize the communication among medical staff and reduce medical errors $[71,72]$.

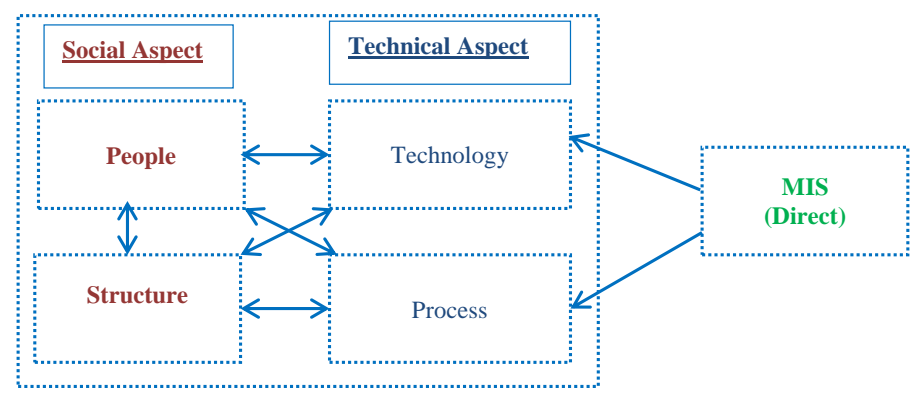

Fig. (3). Socio-technical theory.
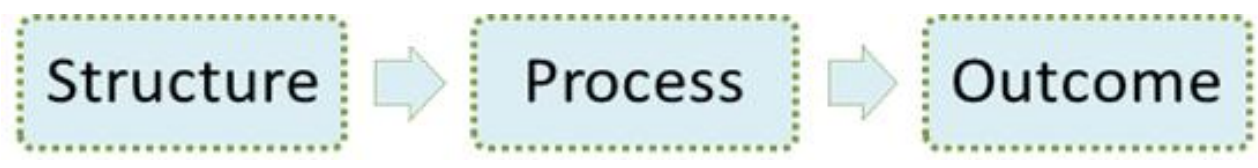

Fig. (4). The Donabedian model.

Many research works recommended using socio-technical theory in healthcare to address the needs of the $21^{\text {st }}$ century [73 - 75]. The characteristics of healthcare are seen in three dimensions, and one of these dimensions is the nature of work that is viewed based on socio-technical theory. Clinical pathways can be seen from the socio-technical theory point of view [76]. Integration between human factors and healthcare quality models can enhance and contribute to performance, patient safety and healthcare quality [77].

\subsection{The Donabedian Model}

Donabedian provides factors that can be useful in strengthening the implementation of clinical pathways to improve teamwork communications in healthcare. The Donabedian model tries to address the question, 'what is quality in medical care [77]. stated that 'if information is the lifeblood of healthcare, then communication is the heart that pumps it'. As a result of this, the Donabedian model has the ability to improve communication in healthcare to improve healthcare quality [17]. This model has three dimensions, Structure, Process, Output, and each dimension has its own factors [17]. Table 6 presents the Donabedian model factors.

Table 6. Donabedian model factors.

\begin{tabular}{|l|c|}
\hline Dimension & Factors \\
\hline \multirow{3}{*}{ Structure } & Internal communication \\
\cline { 2 - 3 } & External communication \\
\hline \multirow{4}{*}{ Process } & Care planning \\
\cline { 2 - 3 } & Information exchange \\
\cline { 2 - 3 } & Decision making \\
\cline { 2 - 3 } & Negotiation \\
\cline { 2 - 3 } & Teaching \\
\cline { 2 - 3 } & Leadership \\
\hline
\end{tabular}


(Table $\square$ ) contd.....

\begin{tabular}{|c|c|}
\hline Dimension & Factors \\
\hline \multirow{7}{*}{ Outcome } & Patient-based \\
\hline & Discharge planning \\
\hline & Reintegration into community \\
\hline & Discharge-based \\
\hline & Disease management \\
\hline & Satisfaction \\
\hline & Achieved patient goals \\
\hline
\end{tabular}

As mentioned in Table 6, Donabedian provides the most appropriate model to be adapted to this research study. However, in structure dimension, when structuring the internal and external communication, internal communication is concerned with the concept of functioning from within policies and procedures while external communications influence how teams coordinated their work with outside agencies and other members during off-work hours. There is a gap that is unfilled; this gap assimilates in communication protocols, which standardized internal and external communication.

The treatment process should be structured based on care plan process on five sub-processes of characteristics: timeline, category of care, outcome criteria, variance record, and inpatient outcome [78]. To support these issues and solve it, the Donabedian model provides factors for these issues, including care planning, information sharing, information exchange, discharge planning, and disease planning.

Patient information, poor communication and coordination, and a lack of standard are other issues that should be resolved. To support and resolve this issue, structuring internal and external communication and the communication process should be standardized by adopting communication protocols. Fig. (5) shows the enhancements over the Donabedian Model and Table 7 presents how Donabedian factors support clinical pathways processes.

Table 7. Donabedian factors support clinical pathways processes.

\begin{tabular}{|c|c|c|c|}
\hline \multicolumn{2}{|r|}{ Issues } & \multirow{2}{*}{ Clinical Pathways Processes } & \multirow{2}{*}{ Donabedian Factors } \\
\hline Literature Review & Preliminary Data & & \\
\hline $\begin{array}{c}\text { Lack of a system that supports } \\
\text { the treatment process }\end{array}$ & $\begin{array}{l}\text { There is no system support treatment process, no } \\
\text { clinical pathways. }\end{array}$ & $\begin{array}{l}\text { Medical process: the aim of this process } \\
\text { is to manage and organize patients' care } \\
\text { plan. } \\
\text { This process can be designed based on its } \\
\text { characteristics: } \\
\text { Timeline. } \\
\text { Category of care. } \\
\text { Outcome criteria. } \\
\text { Variance record. } \\
\text { Inpatient outcome. }\end{array}$ & $\begin{array}{l}\text { - Care planning } \\
\text { - Information sharing } \\
\text { - Information } \\
\text { exchange } \\
\text { - Discharge planning } \\
\text { - Disease planning }\end{array}$ \\
\hline Lack of information & $\begin{array}{l}\text { No computerized system support treatment } \\
\text { process. } \\
\text { Communication is based on the synchronous type. } \\
\text { The system should have three processes to solve } \\
\text { the problems mentioned. Using synchronous types } \\
\text { has a disadvantage in providing information. }\end{array}$ & \begin{tabular}{|} 
Administrative process: the aim of this \\
process is to support the medical process. \\
This process can be designed based on its \\
characteristics: \\
Resources utilization. \\
Leadership. \\
Communication. \\
Care coordination
\end{tabular} & \multirow{2}{*}{\begin{tabular}{|} 
- Teamwork structure \\
- Communication \\
protocols \\
- Internal structure \\
- Policies and \\
procedures \\
- External structure
\end{tabular}} \\
\hline $\begin{array}{l}\text { Poor communication and } \\
\text { coordination }\end{array}$ & - & $\begin{array}{l}\text { Communication process: the aim of this } \\
\text { process is to support medical and } \\
\text { administrative processes. } \\
\text { This process can be designed based on its } \\
\text { characteristics: } \\
\text { Task. } \\
\text { Teamwork. } \\
\text { Knowledge. } \\
\text { Technology. } \\
\text { Context. }\end{array}$ & \\
\hline Delay of communication & - & - & - \\
\hline Lack of standard & $\begin{array}{l}\text { No techniques (protocols) are used to standardize } \\
\text { the communications, such as (briefing, debriefing, } \\
\text { SBAR, etc.) }\end{array}$ & - & - \\
\hline
\end{tabular}




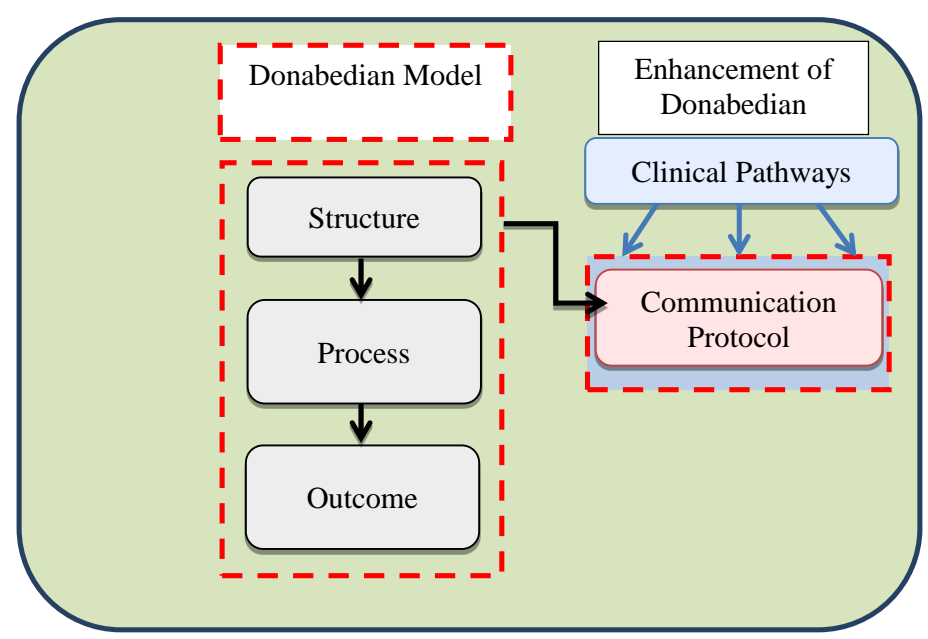

Fig. (5). Enhancement of the donabedian model.

\subsection{Hypotheses}

Fig. (6) presents the proposed model where structure and people make out the social subsystem while technology and tasks make the technical subsystem. According to Giddens, structure is the rules humans follow while interacting with technology. Additionally, Management Information Systems (MIS) affect the technical subsystem according to Lyytinen and Newman [79]. Both the social and technical subsystem depend on each other to achieve rational tasks [80].

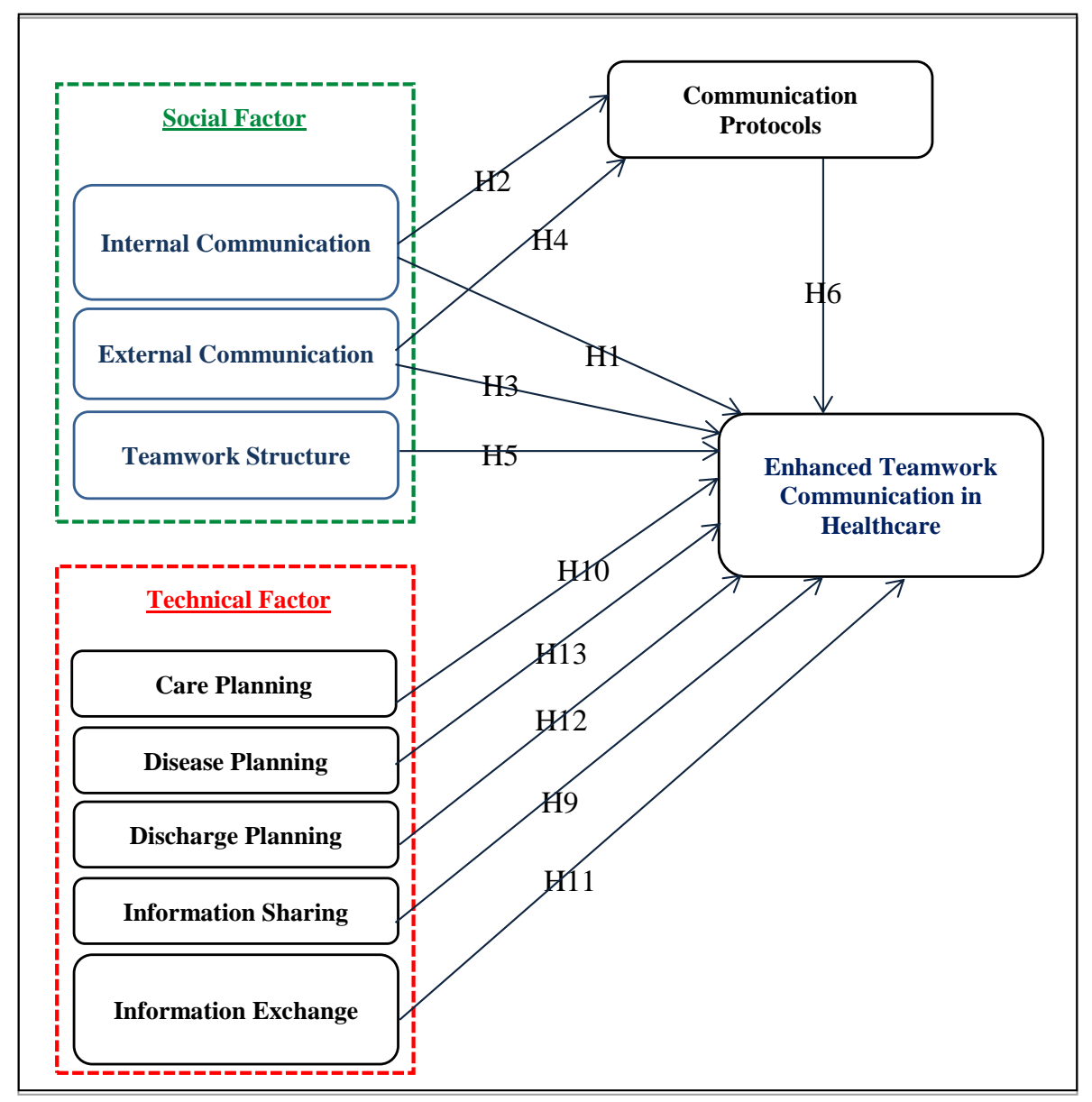

Fig. (6). Proposed research model. 
Internal and external communication is considered an important part of enhancing teamwork communication in healthcare. Internal and external communications were studied and conducted in healthcare by $[33,45,46]$. Teamwork communication in healthcare was also conducted by [8, 29]. This study argues that internal and external communication factors will have an effect on enhancement of teamwork communication in healthcare based on survey participant beliefs. This study develops hypotheses as stated below:

H1: Internal communication will have a positive influence on enhancing teamwork communication in healthcare.

H2: Internal communication will have a positive influence on communication protocols.

H3: External communication will have a positive influence on enhancing teamwork communication in healthcare.

H4: External communication will have a positive influence on communication protocols.

There is a need to apply teamwork structure to HIS design [17]. Structuring teamwork is the application of appropriate processes and resources [81]. That facilitates communication between team members internally and externally [17]. Consequently, teamwork structure has an effect on teamwork communication [17, 82]. This study argues that teamwork structure factor has an effect on the enhancement of teamwork communication in healthcare. This study develops hypotheses as stated below:

H5: Teamwork structure will have a positive influence on enhancing teamwork communication in healthcare.

Communication between individuals is often "informal, disorganized and variable". Therefore, there are a number of tools and aids used to enhance teamwork communication such as communication protocols. Communication protocols are defined as "a set of protocols, which use specific terminologies in teamwork communication" [45]. They enhance teamwork communication, information exchange and teamwork cohesion. These protocols enhance handoff between shifts at hospitals [72]. This study argues that communication protocol factor has an effect on enhancing teamwork communication in healthcare. This study develops hypotheses as stated below:

H6: Communication protocols will have a positive influence on enhancing teamwork communication in healthcare.

H7: Communication protocols will have a mediation role in the association between internal communications and enhance teamwork communication in healthcare.

H8: Communication protocols will have a mediation role in the association between external communications and enhance teamwork communication in healthcare.

Information sharing can be defined as "the amount and frequency of the information shared among teammates" [83]. During incident management, information sharing is crucial for communication and decision-making; therefore, information sharing is key among the technology factors [84]. This study argues that the information sharing factor will has an effect on the enhancement of teamwork communication in healthcare. This study develops a hypothesis as stated below:

H9: Information sharing will have a positive influence on enhancing teamwork communication in healthcare.

Care planning is concerned with addressing all patient care needs and requires high levels of interaction between internal and external team members $[17,29,85]$. Care planning is a technical factor and it has a positive impact on healthcare management, especially during patients' treatment journey [86]. This study argues that the information sharing factor will have an effect on enhancing teamwork communication in healthcare. This study develops a hypothesis as stated below:

H10: Care planning will have a positive influence on enhancing teamwork communication in healthcare.

Ninety percent of healthcare information transactions include information exchange; nonetheless, it was not closely looked at as much as storage [87]. Information exchange that combining and exchanging information results in better value [88]. It has also been defined as "information exchange for the purpose of assisting diagnosis, planning, documenting processes, enabling transfers between areas of responsibility or carry out administrative activities" [89]. However, there is a lack of interest in the literature in designing information exchange systems in healthcare [17]. Information exchange is considered as an important part of enhancing teamwork communication in healthcare. This study argues that the information sharing factor has an effect on the enhancement of teamwork communication in healthcare. This study develops a hypothesis as stated below:

H11: Information exchange will have a positive influence on enhancing teamwork communication in healthcare. 
Hospice care and discharge of the seriously ill requires special procedures and high levels of communications to avoid any mishaps $[17,29,85]$. This study argues that the discharge planning factor has an effect on the enhancement of teamwork communication in healthcare [90]. This study develops a hypothesis as stated below:

H12: Discharge planning will have a positive influence on enhancing teamwork communication in healthcare.

Slowing down illness and managing disease is referred to as disease planning and management. It is critical to communicate healthcare information amongst those diverse teams, which might include psychosocial councilors, spiritual and religious men as well as medical professionals [17, 91]. This study argues that the discharge planning factor has an effect on the enhancement of teamwork communication in healthcare [90, 92]. This study developed a hypothesis as stated below:

H13: Disease planning will have a positive influence on enhancing teamwork communication in healthcare.

\section{RESEARCH METHODOLOGY}

This study used a paper-based questionnaire to collect data from the respondents. The advantages of a paper-based questionnaire are not only that it takes less time and resources to develop, but it is much easier to manage because what you see is what you get [93].

\subsection{Data Collection}

Data were collected in person from physicians and nurses at two university hospitals in the Hashemite Kingdom of Jordan. We distributed survey questionnaires in person to physicians and nurses. In total, 677 questionnaires were distributed and 483 collected. There was a good response rate. The sample size was divided into two samples, 160 questionnaires for Exploratory Factor Analysis (EFA) and 323 for Confirmatory Factor Analysis (CFA). To address the samples' adequacy, we execute the Kaiser-Meyer-Olkin (KMO) test, which measures sample variance. A commendable $\mathrm{KMO}$ of 0.81 indicates very good adequacy.

\subsection{Measurement}

The survey questionnaire uses a five-point Likert-type scale and consists of close-ended questions. The questionnaire consists of 48 questions pertaining to background information as well as social and technical factors. The questions aimed to measure the physicians and nurses' perceptions of teamwork communication in healthcare by implementing electronic clinical pathways. Each construct was assessed using measures validated in previous studies and was further refined and validated through the content validity process and pilot tests. With regards to measurement of constructs, it was measured using five factors adapted from [94], external communication was measured using five factors adapted from [17, 95], teamwork structure was measured using five factors adapted from [82, 96], communication protocols were measured using six factors adapted from $[45,46]$, information sharing was measured using four factors adapted from [97], care planning was measured using five factors adapted from [17, 86], information exchange was measured using six factors adapted from [88, 98], discharge planning was measured using four factors adapted from [17, 90], disease planning was measured using four factors adapted from [92], and finally teamwork communication in healthcare by implementing electronic clinical pathways was measured using four factors adapted from [97]. The content validity process was done by distributing the questionnaires to 6 academic research experts and 4 medical research experts. Upon review of the results, the questionnaire factors were refined.

The social aspect or subsystem was presented by a set of factors to achieve the goals and objectives of this research study. The survey measurement of the social aspect contained the concept of teamwork communication types [17], structuring the teamwork [17] and the standardization of the communication between team members [45].

In contrast, the technical aspect is manifested in a set of factors that facilitate and support the social aspect to achieve the goals and objectives of this research study. The survey measurement of the technical aspect included the concepts of care planning, disease planning, discharge planning, information sharing and information exchange [17] to achieve the goals and objectives of this research study. The scale was articulated and adapted based on the IS literature and previous research works.

\subsection{Descriptive Analysis}

Table 8 shows that most of the respondents in this study were female (64.4\%) and nurses (71.5\%). Most were under age $35(93.8 \%)$ and had a bachelor's degree (72.7\%), and most had less than 5 years' experience in using information 
technology.

Table 8. Demographic profile of respondents.

\begin{tabular}{|c|c|c|}
\hline Categories & Frequency & Percentage \\
\hline Job & - & - \\
\hline - Physician & 92 & 28.5 \\
\hline • Nurse & 231 & 71.5 \\
\hline \multicolumn{3}{|c|}{ Gender } \\
\hline - Male & 115 & 35.6 \\
\hline - Female & 208 & 64.4 \\
\hline \multicolumn{3}{|c|}{ Age } \\
\hline$\cdot 24$ years or below & 72 & 22.3 \\
\hline - 25-34 years & 231 & 71 \\
\hline - 35-44 years & 14 & 4.3 \\
\hline$\cdot 45-54$ & 5 & 1.5 \\
\hline - More than 55 years & 1 & 0.3 \\
\hline Technology experience & - & - \\
\hline - Less than one year & 77 & 23.8 \\
\hline$\cdot 1-5$ years & 150 & 46.4 \\
\hline$\cdot 5-10$ years & 67 & 20.7 \\
\hline - More than 10 years & 29 & 9.0 \\
\hline \multicolumn{3}{|c|}{ Educational qualifications } \\
\hline - Diploma & 23 & 7.1 \\
\hline - Bachelor & 235 & 72.8 \\
\hline - Master & 58 & 18.0 \\
\hline - Doctoral & 7 & 2.2 \\
\hline \multicolumn{3}{|c|}{ Name of hospital } \\
\hline - King Abdu Allah & 146 & 45.2 \\
\hline - Jordan university & 177 & 54.8 \\
\hline
\end{tabular}

\subsection{Assessing the Model Using SmartPLS}

Assessing the model via SmartPLS is generally done through a two steps, involving assessment and structural models [99]. Assessing the measurement examines the validity and reliability of the relationship between latent and the associated observed variables. The structural model was assessed focusing on the relationships between the constructs $[100,101]$.

The SEM PLS-based approach was employed in this study. SmartPLS uses Partial Least Squares (PLS) for variance-based Structural Equation Modeling (SEM) [102]. For data analysis we use Smart PLS 3.2.1 and IBM SPSS Statistics 19.0 because of: 1) PLS-SEM does not work on the assumption that the data is distributed normally, 2) bootstrap resampling carried out by randomly selected observations, 3) the parameter estimates enable the derivation of standard errors. Additionally, the objective of PLS (Partial Least Squares) analysis is in line with the objectives in this study, which include predicting whether the factors play a role in enhancing teamwork communication in healthcare through the implementation of electronic clinical pathways [103, 104].

\subsection{Assessing of the Measurement Model}

In this model, all constructs were reflective; thus, to assess the measurement model, the criteria for assessing of the reflective measurement model had to be considered. The reflective measurement model evaluated reliability and validity, as measured by Composite Reliability (CR) and Average Variance Extracted (AVE) [101, 105]. In the assessment of indicator reliability, the loading of each indicator on its associated latent construct should be higher than 0.7 [106]. However, a loading between 0.4 and 0.7 can be considered acceptable if the CR and AVE of the associated construct are higher than the threshold [101].

First, the constructs meet the requirements of reliability given that their loading is, in general, greater than 0.7 as shown in Table 8. To accomplish this result, we carried out a process of item-trimming with some tweaking of clinical pathways, EC, and IE constructs. In addition, we kept some IS and clinical pathwaysL factors that had weak loading to 
support the validity of the scale and because their Cronbach's Alpha is high. Second, because all constructs' composite reliability is greater than 0.7 , they have construct reliability. Third, Table 9 shows that the Average Variance Extracted (AVE) is greater than 0.5; therefore, the constructs have a convergent validity. Finally, Tables $\mathbf{1 0}$ and $\mathbf{1 1}$ show that all variables realize discriminant validity following both the Fornell-Lacker and the HTMT.90 [107, 108].

Table 9. Measurement model results

\begin{tabular}{|c|c|c|c|c|c|}
\hline Construct & Factors & Factor Loading & CR & Cronbach's Alpha & AVE \\
\hline \multirow{5}{*}{ Internal Communication } & IC1 & 0.711 & \multirow{5}{*}{0.878} & \multirow{5}{*}{0.826} & \multirow{5}{*}{0.591} \\
\hline & IC2 & 0.812 & & & \\
\hline & IC3 & 0.817 & & & \\
\hline & IC4 & 0.768 & & & \\
\hline & IC5 & 0.729 & & & \\
\hline \multirow{4}{*}{ External Communication } & EC2 & 0.742 & \multirow{4}{*}{0.871} & \multirow{4}{*}{0.801} & \multirow{4}{*}{0.628} \\
\hline & EC3 & 0.849 & & & \\
\hline & EC4 & 0.806 & & & \\
\hline & EC5 & 0.768 & & & \\
\hline \multirow{4}{*}{ Communication Protocols } & CLINICAL PATHWAYS3 & 0.740 & \multirow{4}{*}{0.837} & \multirow{4}{*}{0.739} & \multirow{4}{*}{0.562} \\
\hline & CLINICAL PATHWAYS4 & 0.801 & & & \\
\hline & CLINICAL PATHWAYS5 & 0.759 & & & \\
\hline & CLINICAL PATHWAYS6 & 0.696 & & & \\
\hline \multirow{5}{*}{ Teamwork Structure } & TS1 & 0.658 & \multirow{5}{*}{0.875} & \multirow{5}{*}{0.820} & \multirow{5}{*}{0.585} \\
\hline & TS2 & 0.803 & & & \\
\hline & TS3 & 0.846 & & & \\
\hline & TS4 & 0.791 & & & \\
\hline & TS5 & 0.711 & & & \\
\hline \multirow{6}{*}{ Care Planning } & CLINICAL PATHWAYSL1 & & \multirow{6}{*}{0.890} & \multirow{6}{*}{0.845} & \multirow{6}{*}{0.620} \\
\hline & - & 0.685 & & & \\
\hline & CLINICAL PATHWAYSL2 & 0.774 & & & \\
\hline & CLINICAL PATHWAYSL3 & 0.862 & & & \\
\hline & CLINICAL PATHWAYSL4 & 0.843 & & & \\
\hline & CLINICAL PATHWAYSL5 & 0.762 & & & \\
\hline \multirow{4}{*}{ Discharge Planning } & DP1 & 0.806 & \multirow{4}{*}{0.897} & \multirow{4}{*}{0.846} & \multirow{4}{*}{0.620} \\
\hline & DP2 & 0.816 & & & \\
\hline & DP3 & 0.791 & & & \\
\hline & DP4 & 0.733 & & & \\
\hline & DPL1 & 0.850 & & & \\
\hline Dicenco Dlanning & DPL2 & 0.864 & 0867 & 0705 & 0685 \\
\hline Disease Planning & DPL3 & 0.833 & 0.807 & 0.195 & 0.085 \\
\hline & DPL4 & 0.760 & & & \\
\hline & IS1 & 0.706 & & & \\
\hline Unformation Sharing & IS2 & 0.762 & 0797 & 0662 & 0498 \\
\hline Information Sharıng & IS3 & 0.728 & 0.191 & 0.002 & 0.498 \\
\hline & IS4 & 0.617 & & & \\
\hline & IE1 & 0.781 & & & \\
\hline Informotion Exupon & IE2 & 0.771 & 0,010 & 0751 & 0572 \\
\hline Intormation Exchange & IE4 & 0.767 & 0.842 & 0.151 & $0.5 / 2$ \\
\hline & IE5 & 0.703 & & & \\
\hline & TCE1 & 0.850 & & & \\
\hline Teamwork Communication & TCE2 & 0.793 & 0804 & 0811 & 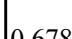 \\
\hline Enhancement & TCE3 & 0.849 & 0.894 & 0.841 & $0.0 / 8$ \\
\hline & TCE4 & 0.798 & & & \\
\hline
\end{tabular}

Note: CR: Composite Reliability; AVE: Average Variance Extracted 
Table 10. Discriminant validity: Fornell-lacker criterion.

\begin{tabular}{|c|c|c|c|c|c|c|c|c|c|c|}
\hline & CLINICAL PATHWAYS & CLINICAL PATHWAYSL & DP & DPL & EC & IC & IE & IS & TCE & TS \\
\hline CLINICAL PATHWAYS & $\mathbf{0 . 7 5 0}$ & - & - & - & - & - & - & - & - & - \\
\hline CLINICAL PATHWAYSL & 0.594 & $\mathbf{0 . 7 8 8}$ & - & - & - & - & - & - & - & - \\
\hline DP & 0.622 & 0.575 & $\mathbf{0 . 7 8 7}$ & - & - & - & - & - & - & - \\
\hline DPL & 0.618 & 0.598 & 0.645 & $\mathbf{0 . 8 2 8}$ & - & - & - & - & - & - \\
\hline EC & 0.510 & 0.501 & 0.461 & 0.468 & $\mathbf{0 . 7 9 2}$ & - & - & - & - & - \\
\hline IC & 0.557 & 0.450 & 0.462 & 0.427 & 0.587 & $\mathbf{0 . 7 6 9}$ & - & - & - & - \\
\hline IE & 0.491 & 0.536 & 0.528 & 0.468 & 0.391 & 0.443 & $\mathbf{0 . 7 5 6}$ & - & - & - \\
\hline IS & 0.499 & 0.573 & 0.557 & 0.514 & 0.480 & 0.469 & 0.481 & $\mathbf{0 . 7 0 5}$ & - & - \\
\hline TCE & 0.684 & 0.676 & 0.679 & 0.667 & 0.620 & 0.603 & 0.500 & 0.677 & $\mathbf{0 . 8 2 3}$ & - \\
\hline TS & 0.651 & 0.652 & 0.642 & 0.579 & 0.566 & 0.558 & 0.559 & 0.575 & 0.720 & $\mathbf{0 . 7 6 5}$ \\
\hline
\end{tabular}

Table 11. Discriminant validity: Heterotrait-Monotrait Ratio (HTMT).

\begin{tabular}{|c|c|c|c|c|c|c|c|c|c|c|}
\hline- & Clinical Pathways & Clinical Pathways & DP & DPL & EC & IC & IE & IS & TCE & TS \\
\hline Clinical Pathways & - & - & - & - & - & - & - & - & - & - \\
\hline Clinical Pathways & 0.752 & - & - & - & - & - & - & - & - & - \\
\hline DP & 0.812 & 0.703 & - & - & - & - & - & - & - & - \\
\hline DPL & 0.783 & 0.707 & 0.788 & - & - & - & - & - & - & - \\
\hline EC & 0.660 & 0.609 & 0.576 & 0.568 & - & - & - & - & - & - \\
\hline IC & 0.709 & 0.536 & 0.562 & 0.504 & 0.721 & - & - & - & - & - \\
\hline IE & 0.650 & 0.672 & 0.682 & 0.585 & 0.497 & 0.559 & - & - & - & - \\
\hline IS & 0.716 & 0.769 & 0.769 & 0.690 & 0.657 & 0.631 & 0.679 & & - & - \\
\hline TCE & 0.866 & 0.799 & 0.828 & 0.788 & 0.753 & 0.717 & 0.625 & 0.802 & - & - \\
\hline TS & 0.839 & 0.786 & 0.795 & 0.695 & 0.698 & 0.676 & 0.709 & 0.784 & 0.865 & - \\
\hline
\end{tabular}

\subsection{Assessment of Structural Model}

The R-square (R) measure for the endogenous constructs and the path coefficients tests were needed to complete a preliminary assessment of the structural and conceptual models. First, endogenous variables. Table 12 shows the results of the model prediction quality. The results indicated that $\mathrm{R}^{2}$ of communication protocols, teamwork communication enhancement was 0.737 and 0.362 , respectively. These substantial numbers prove the model's predictive ability according to [100] and [105, 109].

Table 12. Structural model: $R$-square $\left(\mathbf{R}^{2}\right)$.

\begin{tabular}{|c|c|}
\hline- & R-Square \\
\hline Clinical pathways & 0.362 \\
\hline TCE & 0.737 \\
\hline
\end{tabular}

Second, direct effects testing of the hypothesis for this study were verified by evaluating the statistical importance of the path coefficients computed by means of the bootstrap resampling method utilizing 5000 samples as shown in Table 13 [100, 105]. define the bootstrap resampling as a non-parametric method for estimating the precision of the SMART-PLS estimates.

Table 13. Structural model: Direct effect.

\begin{tabular}{|c|c|c|c|c|c|c|}
\hline- & $\begin{array}{c}\text { Original Sample } \\
(\mathbf{O})\end{array}$ & Sample Mean (M) & $\begin{array}{c}\text { Standard Error } \\
(\text { STERR) }\end{array}$ & $\begin{array}{c}\text { T Statistics } \\
(\mid \mathbf{O} / \text { STERR } \mid)\end{array}$ & $\boldsymbol{P}$ Values & Significant Level \\
\hline clinical pathways -> TCE & 0.126 & 0.128 & 0.059 & 2.157 & 0.031 & $* *$ \\
\hline clinical pathwaysL-> TCE & 0.130 & 0.131 & 0.056 & 2.331 & 0.020 & $* *$ \\
\hline DP -> TCE & 0.130 & 0.133 & 0.057 & 2.299 & 0.022 & $* *$ \\
\hline DPL -> TCE & 0.145 & 0.145 & 0.055 & 2.646 & 0.008 & $* *$ \\
\hline EC -> clinical pathways & 0.278 & 0.284 & 0.092 & 3.026 & 0.002 & $* *$ \\
\hline EC -> TCE & 0.125 & 0.127 & 0.049 & 2.565 & 0.010 & $* *$ \\
\hline IC -> clinical pathways & 0.394 & 0.389 & 0.075 & 5.275 & 0.000 & $* * *$ \\
\hline
\end{tabular}


(Table प्) contd.....

\begin{tabular}{|c|c|c|c|c|c|c|}
\hline- & $\begin{array}{c}\text { Original Sample } \\
(\text { (O) }\end{array}$ & Sample Mean (M) & $\begin{array}{l}\text { Standard Error } \\
\text { (STERR) }\end{array}$ & $\begin{array}{c}\text { T Statistics } \\
(\mid \text { O/STERR } \mid)\end{array}$ & $P$ Values & Significant Level \\
\hline IC -> TCE & 0.116 & 0.112 & 0.044 & 2.632 & 0.009 & $* *$ \\
\hline IE -> TCE & -0.062 & -0.061 & 0.048 & 1.298 & 0.194 & NS \\
\hline IS -> TCE & 0.215 & 0.217 & 0.054 & 3.981 & 0.000 & $* *$ \\
\hline TS -> TCE & 0.162 & 0.157 & 0.068 & 2.398 & 0.017 & $* *$ \\
\hline
\end{tabular}

Note: ${ }^{*} p<0.1 ; * * p<0.05 ; * * * p<0.01$; NS Not Significant.

Third, indirect effects is one of the assessment criterions used to test mediation [110] as recommended by [111, 112]. Based on the new concepts of analysis of the effect of mediation, this can be a direct effect or an indirect effect (indirect relationship) [112]. In this research study, there is no indirect effect for communication (internal and external) on the enhancement of teamwork communication through communication protocols. According to [108], if VAF > $80 \%$, full mediation is achieved. However, partial mediation is obtained when $20 \%>=\mathrm{VAF}<=80 \%$. No mediation is obtained when $\mathrm{VAF}<20 \%$. Table $\mathbf{1 4}$ confirms this result.

Table 14. Indirect effect.

\begin{tabular}{|c|c|c|c|c|c|}
\hline- & Original Sample (O) & Sample Mean (M) & Standard Error (STERR) & T Statistics (|O/STERR|) & $\boldsymbol{P}$-Values \\
\hline EC -> TCE & 0.035 & 0.036 & 0.020 & 1.783 & 0.075 \\
\hline IC -> TCE & 0.050 & 0.051 & 0.027 & 1.854 & 0.064 \\
\hline
\end{tabular}

Fourth, after assessing the path coefficient and $\mathrm{R}^{2}$ values, the next step is to evaluate the effect sizes to investigate the impact and contribution of each exogenous construct towards endogenous latent variables. $f^{2}$ results are shown in Table 15.

Table 15. Effect size $\left(f^{2}\right)$.

\begin{tabular}{|c|c|c|c|c|c|c|}
\hline - & Original Sample (O) & Sample Mean (M) & $\begin{array}{c}\text { Standard Error } \\
\text { (STERR) }\end{array}$ & T Statistics (|O/STERR|) & $P$ Values & \begin{tabular}{|c|} 
Effect \\
Size
\end{tabular} \\
\hline clinical pathways $->$ TCE & 0.026 & 0.033 & 0.027 & 0.972 & 0.331 & Small \\
\hline clinical pathways L -> TCE & 0.028 & 0.034 & 0.026 & 1.107 & 0.268 & Small \\
\hline DP $->$ TCE & 0.028 & 0.034 & 0.026 & 1.058 & 0.290 & Small \\
\hline DPL -> TCE & 0.037 & 0.043 & 0.030 & 1.231 & 0.218 & Small \\
\hline EC -> clinical pathways & 0.079 & 0.094 & 0.060 & 1.331 & 0.183 & Small \\
\hline $\mathrm{EC}->\mathrm{TCE}$ & 0.032 & 0.038 & 0.027 & 1.212 & 0.226 & Small \\
\hline IC -> clinical pathways & 0.160 & 0.166 & 0.067 & 2.370 & 0.018 & Medium \\
\hline IC $->$ TCE & 0.027 & 0.030 & 0.021 & 1.287 & 0.198 & Small \\
\hline IE -> TCE & 0.009 & 0.014 & 0.015 & 0.563 & 0.573 & -- \\
\hline IS -> TCE & 0.095 & 0.103 & 0.048 & 1.957 & 0.050 & Small \\
\hline TS $->$ TCE & 0.037 & 0.043 & 0.033 & 1.132 & 0.258 & Small \\
\hline
\end{tabular}

\section{DISCUSSION}

Through the gathering and analysis of relevant data, this study shows that internal and external communications are an important trigger for communication protocols, and that teamwork communication in healthcare may be enhanced by implementing electronic clinical pathways. Based on the survey participants beliefs and the presented analysis, the managerial and theoretical implications of the relationships seen across those constructs are discussed as follows.

With regards to $\mathrm{H} 1$, the researchers believe based on empirical evidence that internal communication influences the enhancement of teamwork communication in healthcare. This result is corroborated by earlier work [113], which encourages structuring communication among team members. Communication will enhance the performance and quality of healthcare that is needed to structure internal communication. In addition, we believe internal communication, H2, either enhances or influences communication protocols. This result is similar to the findings reported by $[45,114]$, which shows that internal communication supports communication protocols. On the other hand, external communication, $\mathrm{H} 3$, has an influence on the enhancement of teamwork communication in healthcare, while $\mathrm{H} 4$ confirms that external communication may lead to a positive influence on communication protocols.

Additionally, communication protocols may have a positive influence on enhancing teamwork communication in healthcare, H6. This result is similar to the findings reported by $[45,114]$, which encourages the structuring and redesigning of communication among team members based on communication protocols. The results for $\mathrm{H} 7$ and $\mathrm{H} 8$ 
indicates that the communication protocols could mediate the relationship between internal and external communication and teamwork communication enhancement. According to the participants beliefs, communication protocols have no significant effect as a mediator as shown by the result of an indirect effect. Communication protocols were found to be insignificant. The result was insignificant because the current research on communication protocols studied a manual system, not computerized systems like in the case of electronic clinical pathways. Also, the research by [45] investigated and studied communication protocols alone without merging them with the electronic clinical pathways.

This paper proves, based on participants beliefs, that teamwork structure, H5, has a positive influence on the enhancement of teamwork communication. In addition, they believe information sharing influences teamwork communication enhancement, H9. This result shows the significance of information sharing's influence on supporting teamwork communication enhancement. They also believe, that care planning has a positive influence on teamwork communication enhancement, H10. Likewise, they believe information exchange H11 has a positive influence on teamwork communication enhancement. In this case, the participants believe that information exchange can be done by activating the information sharing process.

Finally, the participants believe, both discharge (H12) and disease planning (H13) have a positive influence on teamwork communication enhancement. This finding corroborated by earlier studies $[17,115,116]$.

This study has some limitations. First, this research was carried out in specific hospitals, which might limit the generalization of the results to other hospitals. Second, this research considered only physicians and nurses, who are the main users of clinical pathways. However, the study should be conducted to involve other healthcare stakeholders, such as administrators.

Nonetheless, and despite the limitations, this paper highlights many directions for future work such as the use of information exchange and communication protocols as mediation factors, which are likely to enhance teamwork communication by implementing electronic pathways.

\section{CONCLUSION}

The study addressed the factors that affect teamwork communication in healthcare by formulating a model according to the Socio-Technical Theory (STT) and Donabedian model. This study's most important contribution is the development of a model that presents the attitude and beliefs of physicians and nurses in two hospitals in Jordan. The developed conceptual prototype presents the concept of electronic clinical pathways by merging communication protocols. Recommendations for Jordanian hospitals to apply and implement electronic clinical pathways are provided.

\section{AUTHORS' CONTRIBUTIONS}

Dr. Ibrahim conceived the main idea for this work. Literature, data collection and analysis were done by Wasef Mater. Dr. Aldwairi contributed to the statistical analysis, results and discussion, submission and reviews, and final write-up.

\section{ETHICS APPROVAL AND CONSENT TO PARTICIPATE}

Not applicable.

\section{HUMAN AND ANIMAL RIGHTS}

No animals/humans were used for studies that are the basis of this research.

\section{CONSENT FOR PUBLICATION}

Not applicable.

\section{CONFLICT OF INTEREST}

The authors declare no conflict of interest, financial or otherwise. 


\section{ACKNOWLEDGMENTS}

This work was supported in part by the University Technology Malaysia and in part by Zayed University Research Office, Research Cluster Award \#17079.

\section{REFERENCES}

[1] Yamazaki T, Ikeda M, Umemoto K. Enhancement of healthcare quality using clinical-pathways activities. VINE J Inform Knowledge 2011; 41(1): 63-75.

[2] Wakamiya S, Yamauchi K. What are the standard functions of electronic clinical pathways? Int J Med Inform 2009; 78(8): 543-50. [http://dx.doi.org/10.1016/j.ijmedinf.2009.03.003] [PMID: 19345608]

[3] Logan J. Electronic health information system implementation models - a review. Stud Health Technol Inform 2012; 178 : 117-23. [PMID: 22797029]

[4] Deneckere S, Euwema M, Van Herck P, et al. Care pathways lead to better teamwork: Results of a systematic review. Soc Sci Med 2012; 75(2): 264-8.

[http://dx.doi.org/10.1016/j.socscimed.2012.02.060] [PMID: 22560883]

[5] Barretto S, Warren J, Stumptner M, Schrefl M, Quirchmayr G, Nield S. Proceedings of the 35th Annual Hawaii International Conference on 2002; Washington: IEEE 2002.

[http://dx.doi.org/10.1109/HICSS.2002.994116]

[6] Lee HW, Ramayah T, Zakaria N. External factors in Hospital Information System (HIS) adoption model: A case on Malaysia. J Med Syst 2012; 36(4): 2129-40 [http://dx.doi.org/10.1007/s10916-011-9675-4] [PMID: 21384267]

[7] Yazdi S. An Ontology Based Framework for Modeling Healthcare Teams. M.Sc. diss., University of Ottawa: Ottaw 2012.

[8] Al-Salamah H, Gray A, Morrey D. Mapping the integrated care pathway into BPM for health case management.S-BPM ONE-Education and Industrial Developments. Springer 2012; pp. 106-20. [http://dx.doi.org/10.1007/978-3-642-29294-1_8]

[9] Al-Salamah H. Bath PA, Petersson G, Steinschaden T. Change management along the Integrated Care Pathway (ICP). In: The $14^{\text {th }}$ International Symposium for Health Information Management Research (iSHIMR); Kalmar, Sweden, University of Kalmar. 2009.

[10] Quaglini S, Sacchi L, Lanzola G, Viani N. Personalization and patient involvement in decision support systems: Current trends. Yearb Med Inform 2015; 10(1): 106-18. [http://dx.doi.org/10.15265/IY-2015-015] [PMID: 26293857]

[11] Mattia A. A multi-dimensional view of socio-technical information systems research and technochange. Review of Business Information Systems 2011; 15(4): 11-8. [RBIS]. [http://dx.doi.org/10.19030/rbis.v15i4.6008]

[12] Brooks P, El-Gayar O, Sarnikar S. A framework for developing a domain specific business intelligence maturity model: Application to healthcare. Int J Inf Manage 2015; 35(3): 337-45.

[http://dx.doi.org/10.1016/j.ijinfomgt.2015.01.011]

[13] Koppel R, Metlay JP, Cohen A, et al. Role of computerized physician order entry systems in facilitating medication errors. JAMA 2005; 293(10): 1197-203. [http://dx.doi.org/10.1001/jama.293.10.1197] [PMID: 15755942]

[14] Piscotty RJ, Kalisch B. The relationship between electronic nursing care reminders and missed nursing care. Comput Inform Nurs 2014; 32(10): 475-81.

[http://dx.doi.org/10.1097/CIN.0000000000000092] [PMID: 25119428]

[15] Donabedian A. The quality of care. How can it be assessed? JAMA 1988; 260(12): 1743-8. [http://dx.doi.org/10.1001/jama.1988.03410120089033] [PMID: 3045356]

[16] Donabedian A. Evaluating the quality of medical care. 1966. Milbank Q 2005; 83(4): 691-729. [http://dx.doi.org/10.1111/j.1468-0009.2005.00397.x] [PMID: 16279964]

[17] Kuziemsky CE, Borycki EM, Purkis ME, et al. An interdisciplinary team communication framework and its application to healthcare 'eteams' systems design. BMC Med Inform Decis Mak 2009; 9(1): 43. [http://dx.doi.org/10.1186/1472-6947-9-43] [PMID: 19754966]

[18] AL-Salamah H. Supporting integrated care pathways with workflow technology. PhD diss, Wales, UK: Cardiff University 2012.

[19] Ward MM, Jaana M, Bahensky JA, Vartak S, Wakefield DS. Clinical information system availability and use in urban and rural hospitals. J Med Syst 2006; 30(6): 429-38. [http://dx.doi.org/10.1007/s10916-006-9014-3] [PMID: 17233155]

[20] Lenz R, Reichert M. IT support for healthcare processes - premises, challenges, perspectives. Data Knowl Eng 2007; 61(1): 39-58. [http://dx.doi.org/10.1016/j.datak.2006.04.007]

[21] Swenson KD, Palmer N, Silver B. Taming the Unpredictable: Real World Adaptive Case Management: Case Studies and Practical Guidance. 
USA: Future Strategies Inc. 2011.

[22] Department of Health., The NHS plan: A plan for investment, a plan for reform in London: 2000, pp. 144

[23] Majidi M, Mahdavi H, Siamian H. Patients' information needs in affiliated hospitals of Tehran University of Medical Sciences. Library Philosophy and Practice 2012; 723 Available from: 2012.http://digitalcommons.unl.edu/libphilprac/723

[24] Luxford K, Safran DG, Delbanco T. Promoting patient-centered care: A qualitative study of facilitators and barriers in healthcare organizations with a reputation for improving the patient experience. Int J Qual Health Care 2011; 23(5): 510-5. [http://dx.doi.org/10.1093/intqhe/mzr024] [PMID: 21586433]

[25] Sadeghi P, Kuziemsky C, Benyoucef M. Towards a readiness model for health 2.0. Proceedings of the International Conference on Management of Emergent Digital EcoSystems 2011; ACM Digital Library: San Francisco, California 2011.

[26] Kuziemsky CE, Varpio L. A model of awareness to enhance our understanding of interprofessional collaborative care delivery and health information system design to support it. Int J Med Inform 2011; 80(8): e150-60. [http://dx.doi.org/10.1016/j.ijmedinf.2011.01.009] [PMID: 21317027]

[27] Avison D, Young T. Time to rethink health care and ICT? Commun ACM 2007; 50(6): 69-74. [http://dx.doi.org/10.1145/1247001.1247008]

[28] Foshay N, Kuziemsky C. Towards an implementation framework for business intelligence in healthcare. Int J Inf Manage 2014; 34(1): 20-7. [http://dx.doi.org/10.1016/j.ijinfomgt.2013.09.003]

[29] Pirnejad H, Niazkhani Z, Berg M, Bal R. Intra-organizational Communication in Healthcare. Meth Inf Med 2008; 47: 336-45. [PMID: 18690367]

[30] Perreault LE, Metzger JB. A pragmatic framework for understanding clinical decision support. J Healthc Inf Manag 1999; 13 : 5-22.

[31] Saultz JW. Defining and measuring interpersonal continuity of care. Ann Fam Med 2003; 1(3): 134-43. [http://dx.doi.org/10.1370/afm.23] [PMID: 15043374]

[32] Salas E, King HB, Rosen MA. Improving teamwork and safety: Toward a practical systems approach, a commentary on Deneckere et al. Soc Sci Med 2012; 75(6): 986-9. [http://dx.doi.org/10.1016/j.socscimed.2012.02.055] [PMID: 22627017]

[33] Coiera E. Communication systems in healthcare. Clin Biochem Rev 2006; 27(2): 89-98. [PMID: 17077879]

[34] Bitter J, van Veen-Berkx E, Gooszen HG, et al. Multidisciplinary teamwork is an important issue to healthcare professionals. Team Perform Manage 2013; 19(5/6): 263-78. [http://dx.doi.org/10.1108/TPM-11-2012-0041]

[35] Buljac-Samardzic M, Dekker-van Doorn CM, van Wijngaarden JD, van Wijk KP. Interventions to improve team effectiveness: A systematic review. Health Policy 2010; 94(3): 183-95. [http://dx.doi.org/10.1016/j.healthpol.2009.09.015] [PMID: 19857910]

[36] Parker J, Coiera E. Improving clinical communication: A view from psychology. J Am Med Inform Assoc 2000; 7(5): 453-61. [http://dx.doi.org/10.1136/jamia.2000.0070453] [PMID: 10984464]

[37] Kuziemsky CE, Varpio L. Describing the clinical communication space through a model of common ground: 'you don't know what you don't know'. AMIA Annu Symp Proc 2010; 407-11.

[38] Manojlovich M, Adler-Milstein J, Harrod M, et al. The effect of health information technology on health care provider communication: A mixed-method protocol. JMIR Res Protoc 2015; 4(2): e72. [http://dx.doi.org/10.2196/resprot.4463] [PMID: 26068442]

[39] Vanhaecht K. The impact of clinical pathways on the organisation of care processes. Katholieke Universiteit Leuven Leuven 2007 ; p. 170.

[40] Li W, Liu K, Yang H, Yu C. Integrated clinical pathway management for medical quality improvement - based on a semiotically inspired systems architecture. Eur J Inf Syst 2014; 23(4): 400-17.

[41] Vanhaecht K, Panella M, Van Zelm R, Sermeus W. What about care pathways. Care of Dying.A pathway to excellence 2011; 2-12.

[42] Lippi G, Simundic A-M, Mattiuzzi C. Overview on patient safety in healthcare and laboratory diagnostics. Biochem Med (Zagreb) 2010; 20(2): 131-42. [http://dx.doi.org/10.11613/BM.2010.015]

[43] Panella M, Van Zelm R, Sermeus W, Vanhaecht K, et al. Care pathways for the organization of patients' care. Bulletin: Economics, Organisation and Informatics in Healthcare 2012; 28(2): 111-22. [http://dx.doi.org/10.2478/v10221-011-0026-z]

[44] Carayon P, Alyousef B, Xie A. Human Factors and Ergonomics in Health Care. In: Salvendy G, Ed. Handbook of Human Factors and Ergonomics. $4^{\text {th }}$ ed.. United States:: Wiley Online Library 2012. [http://dx.doi.org/10.1002/9781118131350.ch57]

[45] Lo L. Teamwork and Communication in Healthcare. Canadian Patient Safety Institute Edmonton 2011; p. 68.

[46] Battles J, King HB. TeamSTEPPS Teamwork Perceptions Questionnaire (T-TPQ) Manual. Washington, DC: American Institute for Research 2010 
[47] Hwang J-I, Ahn J. Teamwork and clinical error reporting among nurses in Korean hospitals. Asian Nurs Res (Korean Soc Nurs Sci) 2015; 9(1): 14-20. [http://dx.doi.org/10.1016/j.anr.2014.09.002] [PMID: 25829205]

[48] West MA, Lyubovnikova J. Real teams or pseudo teams? The changing landscape needs a better map. Ind Organ Psychol 2012; 5(1): 25-8. [http://dx.doi.org/10.1111/j.1754-9434.2011.01397.x]

[49] Xiao Y, Parker SH, Manser T. Teamwork and collaboration. Rev Hum Factors Ergon 2013; 8(1): 55-102. [http://dx.doi.org/10.1177/1557234X13495181]

[50] Coffey RJ, Richards JS, Remmert CS, LeRoy SS, Schoville RR, Baldwin PJ. An introduction to critical paths. Qual Manag Health Care 2005; 14(1): 46-55. [http://dx.doi.org/10.1097/00019514-200501000-00006] [PMID: 15739581]

[51] De Bleser L, Depreitere R, De Waele K, Vanhaecht K, Vlayen J, Sermeus W. Defining pathways. J Nurs Manag 2006; 14(7): 553-63. [http://dx.doi.org/10.1111/j.1365-2934.2006.00702.x] [PMID: 17004966]

[52] McGreevy J, Otten T, Poggi M, Robinson C, Castaneda D, Wade P. The challenge of changing roles and improving surgical care now: Crew Resource Management approach. Am Surg 2006; 72(11): 1082-7. [PMID: 17120951]

[53] Shoji F, Yano T, Haro A, et al. Assessing a clinical pathway to improve the quality of care in pulmonary resections. Surg Today 2011; 41(6): $787-90$

[http://dx.doi.org/10.1007/s00595-010-4483-x] [PMID: 21626323]

[54] Richter-Ehrenstein C, Heymann S, Schneider A, Vargas Hein O. Effects of a clinical pathway 3 years after implementation in breast surgery. Arch Gynecol Obstet 2012; 285(2): 515-20. [http://dx.doi.org/10.1007/s00404-011-1994-7] [PMID: 21779775]

[55] Rotter T, Kinsman L, James E, et al. The effects of clinical pathways on professional practice, patient outcomes, length of stay, and hospital costs: Cochrane systematic review and meta-analysis. Eval Health Prof 2012; 35(1): 3-27. [http://dx.doi.org/10.1177/0163278711407313] [PMID: 21613244]

[56] Gupta A, Sharda R. Improving the science of healthcare delivery and informatics using modeling approaches. Decis Support Syst 2013; 55(2): 423-7.

[57] Huang Z, Lu X, Duan H, Fan W. Summarizing clinical pathways from event logs. J Biomed Inform 2013; $46(1): 111-27$. [http://dx.doi.org/10.1016/j.jbi.2012.10.001] [PMID: 23085455]

[58] Alexandrou DA, Skitsas IE, Mentzas GN. A holistic environment for the design and execution of self-adaptive clinical pathways. IEEE Trans Inf Technol Biomed 2011; 15(1): 108-18. [http://dx.doi.org/10.1109/TITB.2010.2074205] [PMID: 20876028]

[59] Yang H, Li W, Liu K, Zhang J. Knowledge-based clinical pathway for medical quality improvement. Inf Syst Front 2011; 14(1): 105-17. [http://dx.doi.org/10.1007/s10796-011-9307-z]

[60] Chavan M. Quality management and quality care. Asian J Qual 2011; 12(1): 91-112. [http://dx.doi.org/10.1108/15982681111140570]

[61] Tehrani J, Liu K, Michell V. Ontology modeling for generation of clinical pathways. J Ind Engineer Manag 2012; 5(2): 442. [http://dx.doi.org/10.3926/jiem.586]

[62] Mater W, Ibrahim R. Factors supporting teamwork communication in clinical pathways: Systematic literature review. J Theoretical Appl Inform Technol 2015; 81(3): 481-8.

[63] Mater W, Ibrahim R. Standard processes of electronic clinical pathways that support decision making and teamwork communication. Science International, 2014; 26(3).

[64] Deneckere S, Robyns N, Vanhaecht K, et al. Indicators for follow-up of multidisciplinary teamwork in care processes: Results of an international expert panel. Eval Health Prof 2011; 34(3): 258-77. [http://dx.doi.org/10.1177/0163278710393736] [PMID: 21190951]

[65] Robert G, Greenhalgh T, Macfa lane F, Peacoc KR. Organisational factors influencing technology adoption and assimilation in the NHS: A systematic literature review. Report for the National Institute for Health Research Service Delivery and Organisation programme, 2009.

[66] Oosterholt RI, Simonse LW, Boess SU, Vehmeijer SB. Designing a care pathway model - A case study of the outpatient total hip arthroplasty care pathway. Int J Integr Care 2017; 17(1): 2. [http://dx.doi.org/10.5334/ijic.2429] [PMID: 29042844]

[67] Mater W, Ibrahim R. Situation analysis for clinical pathways and teamwork communication in healthcare. Indian J Sci Technol 2016; 9(28)

[68] Vrijhoef HJ, de Belvis AG, de la Calle M, et al. IT-supported integrated care pathways for diabetes: A compilation and review of good practices. Int J Care Coord 2017; 20(1-2): 26-40 [http://dx.doi.org/10.1177/2053434517714427] [PMID: 28690856]

[69] Schriek M, Türetken O, Kaymak U. A maturity model for care pathways. ECIS 2016.

[70] Mater W, Ibrahim R. Standard processes of electronic clinical pathways that support decision making and teamwork communication. Sci Int 
$2014 ; 26(5): 1947-51$.

[71] Thomas CM, Bertram E, Johnson D. The SBAR communication technique: Teaching nursing students professional communication skills. Nurse Educ 2009; 34(4): 176-80. [http://dx.doi.org/10.1097/NNE.0b013e3181aaba54] [PMID: 19574858]

[72] Haig KM, Sutton S, Whittington J. SBAR: A shared mental model for improving communication between clinicians. Jt Comm J Qual Patient Saf 2006; 32(3): 167-75. [http://dx.doi.org/10.1016/S1553-7250(06)32022-3] [PMID: 16617948]

[73] Sittig DF. A socio-technical model of health information technology-related e-iatrogenesis. In: AMIA Annu Symp Proc. 2008.

[74] Nøhr C, Aarts JE. Information technology in health care: Socio-technical approaches 2010: From safe systems to patient safety. Amsterdam: IOS Press 2010

[75] Aarts J, Callen J, Coiera E, Westbrook J. Information technology in health care: Socio-technical approaches. Int J Med Inform 2010; 79(6): 389-90. [http://dx.doi.org/10.1016/j.ijmedinf.2010.03.006] [PMID: 20403726]

[76] Berg M. Patient care information systems and health care work: A sociotechnical approach. Int J Med Inform 1999; 55(2): 87-101. [http://dx.doi.org/10.1016/S1386-5056(99)00011-8] [PMID: 10530825]

[77] Carayon P, Schoofs Hundt A, Karsh BT, et al. Work system design for patient safety: The SEIPS model. Qual Saf Health Care 2006; 15(Suppl. 1): i50-8.

[http://dx.doi.org/10.1136/qshc.2005.015842] [PMID: 17142610]

[78] Zhen H, Li JS, Yu HY, Zhang XG, Suzuki M, Araki K. Modeling of clinical pathways based on ontology. In: IEEE International Symposium on IT in Medicine \& Education. ITIME'09. 2009, Vol. 1; pp. 1170-4.

[79] Lyytinen K, Newman M. Explaining information systems change: A punctuated socio-technical change model. Eur J Inf Syst 2008; 17(6): 589-613.

[http://dx.doi.org/10.1057/ejis.2008.50]

[80] Morris A. Socio-Technical Systems in ICT: A comprehensive survey. Povo: University of Trento 2009.

[81] Nancarrow SA, Booth A, Ariss S, Smith T, Enderby P, Roots A. Ten principles of good interdisciplinary team work. Hum Resour Health 2013; 11(1): 19 .

[http://dx.doi.org/10.1186/1478-4491-11-19] [PMID: 23663329]

[82] Hamilton H, Chou W-S. The routledge handbook of language and health communication. $1^{\text {st }}$ ed. New York: Routledge, 2014.

[83] Randall KR, Resick CJ, DeChurch LA. Building team adaptive capacity: The roles of sensegiving and team composition. J Appl Psychol 2011; 96(3): 525-40. [http://dx.doi.org/10.1037/a0022622] [PMID: 21319876]

[84] Kim JK, et al. Framework for analyzing Critical Incident Management Systems (CIMS). System Sciences, 2006. HICSS'06. Proceedings of the $39^{\text {th }}$ Annual Hawaii International Conference on. 2006. Kauia: IEEE.

[85] Mouttham A, Kuziemsky C, Langayan D, Peyton L, Pereira J. Interoperable support for collaborative, mobile, and accessible health care. Inf Syst Front 2012; 14(1): 73-85.

[http://dx.doi.org/10.1007/s10796-011-9296-y]

[86] Segars AH, Grover V. Profiles of strategic information systems planning. Inf Syst Res 1999; 10(3): $199-232$. [http://dx.doi.org/10.1287/isre.10.3.199]

[87] Toussaint PJ, Coiera E. Supporting communication in health care. Int J Med Inform 2005; 74(10): 779-81 [http://dx.doi.org/10.1016/j.ijmedinf.2005.04.007] [PMID: 15998598]

[88] Collins CJ, Smith KG. Knowledge exchange and combination: The role of human resource practices in the performance of high-technology firms. Acad Manage J 2006; 49(3): 544-60. [http://dx.doi.org/10.5465/amj.2006.21794671]

[89] Ammenwerth E, Winter A. Strategic information management in hospitals: An introduction to hospital information systems. Springer Science \& Business Media 2004.

[90] Dai YT, Chang Y, Hsieh CY, Tai TY. Effectiveness of a pilot project of discharge planning in Taiwan. Res Nurs Health 2003; $26(1)$ : 53-63. [http://dx.doi.org/10.1002/nur.10067] [PMID: 12532367]

[91] Melby L, Hellesø R. Electronic exchange of discharge summaries between hospital and municipal care from health personnel's perspectives. Int J Integr Care 2010; 10: e039. [http://dx.doi.org/10.5334/ijic.527] [PMID: 20421964]

[92] Glasgow RE, Toobert DJ, Barrera M Jr, Strycker LA. The Chronic Illness Resources Survey: Cross-validation and sensitivity to intervention. Health Educ Res 2005; 20(4): 402-9. [http://dx.doi.org/10.1093/her/cyg140] [PMID: 15572438]

[93] Boyer KK, Olson JR, Calantone RJ, Jackson EC. Print versus electronic surveys: A comparison of two data collection methodologies. J Oper Manage 2002; 20(4): 357-73. [http://dx.doi.org/10.1016/S0272-6963(02)00004-9] 
[94] Tallon PP, Kraemer KL, Gurbaxani V. Executives' perceptions of the business value of information technology: A process-oriented approach. J Manage Inf Syst 2000; 16(4): 145-73. [http://dx.doi.org/10.1080/07421222.2000.11518269]

[95] Van Der Vegt GS, Bunderson JS. Learning and performance in multidisciplinary teams: The importance of collective team identification. Acad Manage J 2005; 48(3): 532-47. [http://dx.doi.org/10.5465/amj.2005.17407918]

[96] Hirst G, Van Knippenberg D, Chen CH, Sacramento CA. How does bureaucracy impact individual creativity? A cross-level investigation of team contextual influences on goal orientation-creativity relationships. Acad Manage J 2011; 54(3): 624-41. [http://dx.doi.org/10.5465/amj.2011.61968124]

[97] Kim M, Sharman R, Cook-Cottone CP, Rao HR, Upadhyaya SJ. Assessing roles of people, technology and structure in emergency management systems: A public sector perspective. Behav Inf Technol 2012; 31(12): 1147-60. [http://dx.doi.org/10.1080/0144929X.2010.510209]

[98] Gold AH, Arvind Malhotra AHS. Knowledge management: An organizational capabilities perspective. J Manage Inf Syst 2001; 18(1): $185-214$. [http://dx.doi.org/10.1080/07421222.2001.11045669]

[99] Henseler J, Hubona G, Ray PA. Using PLS path modeling in new technology research: Updated guidelines. Ind Manage Data Syst 2016; 116(1): 2-20. [http://dx.doi.org/10.1108/IMDS-09-2015-0382]

[100] Chin WW. Commentary: Issues and opinion on structural equation modeling MIS Quarterly, 1998. 22(1): pp. vii-xvi.

[101] Hair JF, Ringle CM, Sarstedt M. PLS-SEM: Indeed a silver bullet. J Mark Theory Pract 2011; 19(2): 139-52. [http://dx.doi.org/10.2753/MTP1069-6679190202]

[102] Ramayah T, Cheah J, Chuahf F, Ting H, Memon MA. Partial Least Squares Structural Equation Modeling (PLS-SEM) using SmartPLS 30: An updated guide and practical guide to statistical analysis. Kuala Lumpur, Malaysia: Pearson 2016.

[103] Wetzels M, Odekerken-Schröder G, Van Oppen C. Using PLS path modeling for assessing hierarchical construct models: Guidelines and empirical illustration. Manage Inf Syst Q 2009; 33(1): 177-95. [http://dx.doi.org/10.2307/20650284]

[104] Hair JF Jr, Hult GTM, Ringle CM Jr. A Primer on Partial Least Squares Structural Equation Modeling (PLS-SEM). $1^{\text {st }}$ Edition ed. United States: Sage Publications 2013.

[105] Chin WW. How to write up and report PLS analyses.Handbook of partial least squares. Springer 2010; pp. 655-90. [http://dx.doi.org/10.1007/978-3-540-32827-8_29]

[106] Hair JF. Multivariate data analysis. United Stetes: Prentice Hall 2010.

[107] Henseler J, Ringle CM, Sarstedt M. A new criterion for assessing discriminant validity in variance-based structural equation modeling. J Acad Mark Sci 2015; 43: 1-21.

[108] Henseler J, Dijkstra PK, Sarstedt M. Common beliefs and reality about PLS comments on Rönkkö and Evermann (2013). Organizational Research Methods Journal 2014; 17: 182-209. [http://dx.doi.org/10.1177/1094428114526928]

[109] Fornell C, Larcker DF. Evaluating structural equation models with unobservable variables and measurement error. J Mark Res 1981; •.•: 39-50. [http://dx.doi.org/10.2307/3151312]

[110] Zhao X, Lynch JG, Chen Q. Reconsidering Baron and Kenny: Myths and truths about mediation analysis. J Consum Res 2010; 37(2): 197-206. [http://dx.doi.org/10.1086/651257]

[111] Preacher KJ, Hayes AF. Asymptotic and resampling strategies for assessing and comparing indirect effects in multiple mediator models. Behav Res Methods 2008; 40(3): 879-91. [http://dx.doi.org/10.3758/BRM.40.3.879] [PMID: 18697684]

[112] Hayes AF. Introduction to mediation, moderation, and conditional process analysis: A regression-based approach. $1^{\text {st }}$ Edition ed. New York: Guilford Press, 2013.

[113] Choi JN, Kim MU. The organizational application of groupthink and its limitations in organizations. J Appl Psychol 1999; 84(2): 297-306. [http://dx.doi.org/10.1037/0021-9010.84.2.297]

[114] Papaspyros SC, Javangula KC, Adluri RK, O’Regan DJ. Briefing and debriefing in the cardiac operating room. Analysis of impact on theatre team attitude and patient safety. Interact Cardiovasc Thorac Surg 2010; 10(1): 43-7. [http://dx.doi.org/10.1510/icvts.2009.217356] [PMID: 19801374]

[115] Kitson NA, Price M, Lau FY, Showler G. Developing a medication communication framework across continuums of care using the Circle of Care Modeling approach. BMC Health Serv Res 2013; 13(1): 418. [http://dx.doi.org/10.1186/1472-6963-13-418] [PMID: 24134454] 
[116] Amaricai E, Nemes D, Suciu O. The need of a computer-based record in the management of osteoarthritis patients. In: $6^{\text {th }}$ IEEE International Symposium on Applied Computational Intelligence and Informatics (SACI), 2011; pp. 391-5. [http://dx.doi.org/10.1109/SACI.2011.5873035]

\section{(C) 2018 Matar et al.}

This is an open access article distributed under the terms of the Creative Commons Attribution 4.0 International Public License (CC-BY 4.0), a copy of which is available at: (https://creativecommons.org/licenses/by/4.0/legalcode). This license permits unrestricted use, distribution, and reproduction in any medium, provided the original author and source are credited. 